Original Article

\title{
ACTION RESEARCH AS A TOOL FOR TRANSFORMATION OF THE PHARMACIST'S PRAXIS IN PRIMARY CARE
}

\author{
GRAZIELLI C. B. DE OLIVEIRAa, MATEUS R. ALVES ${ }^{\mathrm{b}}$, DJENANE RAMALHO-DE-OLIVEIRA ${ }^{\mathrm{c}}$
}

Centro de Estudos em Atenção Farmacêutica (Center for Pharmaceutical Care Studies), Department of Social Pharmacy, College of Pharmacy, Universidade Federal de Minas Gerais, Belo Horizonte, Brazil

Email: graziellicris@gmail.com

Received: 29 Apr 2016 Revised and Accepted: 17 Jan 2017

\section{ABSTRACT}

Objective: Describe and discuss the use of action research in the Pharmaceutical Assistance restructuring of primary care in the city of Lagoa Santa/MG (Brazil), for the implementation of comprehensive medication management services.

Methods: An action research project, based on fortnightly thematic discussions with a group of ten pharmacists, was used as a management tool to foster the engagement and critical reflection of pharmacists involved in the construction of their clinical practice in primary care.

Results: Action research encouraged pharmacists to think about their practices and to perceive the need for a clearer definition of their roles and responsibilities in primary care. The collective development allowed pharmacists to recognise their weaknesses and strengths, identifying themselves as professionals capable of assuming co-responsibility for the pharmacotherapy of the patient. The re-organization of the service was necessary to provide support for actions related to the logistic of medicines, so pharmacists could dedicate time to their clinical practice.

Conclusion: Action research can be an effective instrument of reflection, motivation and empowerment for the pharmacist team to meet the challenges of the Brazilian Unified Health System (Sistema Único de Saúde, SUS).

Keywords: Medication Therapy Management, Comprehensive medication management, Pharmaceutical care, Primary health care, Pharmaceutical services, Action research, Qualitative research

(c) 2016 The Authors. Published by Innovare Academic Sciences Pvt Ltd. This is an open access article under the CC BY license (http://creativecommons.org/licenses/by/4.0/) DOI: http://dx.doi.org/10.22159/ijpps.2017v9i3.16486

\section{INTRODUCTION}

Nowadays the healthcare scenario requires the pharmacist to be more than a supplier of medicines. High morbidity and mortality rates associated with the use of medicines claim for a pharmacist that takes responsibility for the consequences of such use. In Brazilian Public Unified Health System (Sistema Único de Saúde, SUS), as well as in other scenarios, the role of pharmacists is not well defined [1]. In Brazil, the term Pharmaceutical activities involves broad, multidisciplinary and intersectoral activities [2], nevertheless pharmacists' responsibilities still consist of essentially supervising the logistics associated with the acquisition, distribution and delivery of medicines in health facilities, with little participation in direct patient care.

Pharmaceutical Care Practice, proposed by Hepler and Strand (1990), is described as a response to social demands for a professional who takes responsibility for the drug use process in patients' daily lives. It is a patient care professional practice defined as the responsible provision of pharmacological treatments, seeking concrete results that improve patients' quality of life [3]. In this context, Ramalho-de-Oliveira proposes that the professional practice of Pharmaceutical Care should not be understood only as an activity, but as a new way of thinking, being and acting for pharmacists' practitioners [4]. The term Comprehensive Medication Management (CMM), which is the operationalization of pharmaceutical care practice into a health service, is defined as the care standard that ensures each patient's medications (whether they are prescription, nonprescription, alternative, traditional, vitamins, or nutritional supplements) are individually assessed to determine that each medication is appropriate for the patient, effective for the medical condition, safe given the comorbidities and other medications being taken, and able to be taken by the patient as intended [5].

CMM is a service experienced by patients and managers in the reality of healthcare systems when pharmacists accept Pharmaceutical Care practice as their professional mandate. This clinical service can be understood as a technology to promote the rational use of medicines at the daily lives of SUS users, in accordance with the functions of primary health care. It is also a tool enabling standardization of pharmacists' patient care activities involving the use of a rational process to detect problems and make decisions about pharmacotherapy (pharmacotherapy workup), the construction of a therapeutic relationship with the patient, the involvement with the community, the construction of multiprofessional collaborative relationships and follow-up evaluations of the patient demonstrating responsibility for the results of his or her pharmacotherapy [6].

The implementation of CMM service in the SUS demands a reorganization of pharmacists' activities, allowing the professional to act both in the management of medication supplies and patient care, creating spaces and structures to include a new clinical service in the health system. Accomplishing this change requires collective work. It implies acceptance of the complexity of human diversity, becoming a continuous process that considers the environment, personal and professional beliefs, experiences and traditions [7]. The participation of subjects involved in this change will help ensure the convergence of values in the provision of the service. In addition, data collection and analysis, and dissemination of results of the change process may promote new ways of thinking and learning for future changes [8, 9].

Concerning the challenge of restructuring the drug supply and administrative activities for the insertion of the CMM service, the research methodology needs to guarantee the active involvement of pharmacists in the process, seeking to ensure conditions for these professionals to perform the clinical service efficiently and permanently. Hence, this manuscript discusses the use of action research methodology in restructuring pharmacy services to insert CMM services in the city of Lagoa Santa, Minas Gerais, Brazil.

\section{MATERIALS AND METHODS}

Qualitative research is presented as a methodological alternative, focusing on the processes experienced by subjects of a given 
research. Action research is a qualitative methodology widely employed in the healthcare field to train professionals in the development of their practical knowledge [10-12].

This research involves the person who knows the field and the workplace "from inside", considering it as a profound connoisseur of this scenario. According to Ernie Stringer (2014), the main characteristics of Action Research are the knowledge and the understanding of what happens to people and their working process. The goal is to enable them to explore their experiences and increase perceptions of their own situations [13].

The term action research, attributed to Kurt Lewin (1890-1947), came from the assumption that theory can be expressed directly by action [14]. For Lewin, it was not enough just to try to explain things. It was also necessary to change them. This desire led to the development of action research and the awareness that human systems can only be understood and changed if their members take part in this process.

The cyclical spiral process is a typical feature of action research, where cycles of activities form a spiral of continuous and overlapping cycles in which research, action, and evaluation are closely interlinked [15]. Another important component of action research is the critical reflection, capable of initiating changes in behaviours, skills, services and ways of thinking. In the changing scenario of praxis, the main objective is to analyze whether the new practice reflects the important values of professionals or whether the new technology helps them to achieve their goals according to their beliefs [16].

In our paper, field observations were carried out for twenty-six months, and a total of ten pharmacists participated in this study: five involved in administrative and logistic activities, three in the building process of CMM services, one in clinical coordination and another in general coordination. Data was collected through field notes during the entire research process.

Fortnightly meetings were held with the team of pharmacists to discuss processes and practical issues experienced during the change stage. In these meetings, pharmacists were encouraged to share their perspectives and experiences, so that a deeper awareness of the process could emerge. The first author of this paper (one of the pharmacists composing the team) was the person who started the process. In order to deeply explore specific themes, four pharmacists of the team were selected for individual semistructured interviews. For strategic and situational analysis of the project, regular meetings were held among the leaders of pharmacy services (two pharmacy coordinators), as well as between them and the healthcare secretary of the city during the full research period. Data analysis was performed using thematic analysis of all collected data [17-18].

Methodological rigor was guaranteed by the triangulation of different methods of data collection and researcher reflexivity. Moreover, following methodological requirements, themes found during data analysis were taken back to research participants for discussion as a team. This process made it possible to confirm researcher's interpretations and to determine the reflectivity of the team, increasing the trustworthiness of the study.

This project was approved by the Ethics Committee of the Universidade Federal de Minas Gerais-UFMG (report number 25780314.4.0000.0149), and all participants have signed an informed consent form.

\section{Place of study}

The research was conducted from June 2013 to August 2015 in Lagoa Santa/MG (Brazil), a city located in the metropolitan region of Belo Horizonte with a population of 57,990 inhabitants living in an area of $229.3 \mathrm{~km}^{2}$ according to the 2015 census [19].

The municipal health care services are distributed in four Regional, seventeen Basic Healthcare Units and three Support Units; two family health care teams; one home care service team; three mental health care units (psychosocial care center, alcohol and drugs and childcare); one rehabilitation unit; one clinical laboratory; one ambulatory of specialties; one center of dental specialties; and one emergency unit.

At the beginning of our study, we have found a scenario with only two pharmacists. Services at the Department of Pharmacy Services had no standard operating procedures. There was not any documentation of processes or standardisation of practices, and it was recognised only by activities related to drug distribution. Pharmacists worked at the municipal pharmacies with no interdisciplinary interactions. Drug supply, logistic and administrative activities were conducted by one mid-level professional with eventual assistance of a pharmacist, leading to the shortage of medicines in the stocks of pharmacies.

For the construction of CMM services in Lagoa Santa, the clinical pharmacy team received technical support from the Universidade Federal de Minas Gerais (Center for Pharmaceutical Care Studies) at the UFMG.

\section{RESULTS}

Our work began with the admission of the first author of this paper as a manager of the Department of Pharmacy Services in the city of Lagoa Santa. She was granted complete autonomy to restructure the department, with the objective to implement CMM as the major clinical pharmacy service that could be easily integrated with other healthcare services in the primary care ambulatory clinics. A basic premise of the CMM service is its multidisciplinary and interdisciplinary character.

Action research was used as a management instrument for restructuring pharmacy services, promoting empowerment and participation of pharmacists in the implementation of CMM services in primary care. The Department adopted a process of shared coordination: one manager was responsible for administrative duties and the other for clinical services. Influenced by the dialogical nature of action research, managers sought to establish goals, demand results and provide the necessary support for the service's implementation. Besides, the coordinators were open to dialogue and critiques, valuing the autonomy and freedom of the participating pharmacists.

Data analysis revealed five major themes. They address the place of pharmacists in primary care, the functions they play in this scenario and the role of action research in the empowerment of this professional.

\section{Redefining the pharmacist's role in primary care}

At the beginning of the research, pharmacists' activities encompassed mostly acquisition and delivery of prescribed drugs. The role of the pharmacist was poorly understood by other health care professionals, culminating in the insecurity of some pharmacists concerning their work with patients and with the healthcare team.

"[. ] I do not remember seeing anything like that [caring for patients] in college. And we. so, what will I do? What can I do? What can't I do? How far can I go? So I keep groping."

\section{Pharmacist 1}

In the insertion of CMM services, action research proved to be an important tool to stimulate the reflection of the team regarding the pharmacist's role, as well as on the new function we wanted to build in the health care system. Pharmacist 2 demonstrates that:

"But what is empowerment? First, we have to recognize ourselves, and I think that's the part we fail a little bit. We know what we are not. But we know what we are? What are our potentialities? Our real potentialities... And this I think it's something we really have to build, to build a stronger profile. Because only when we recognize ourselves, we know our limits and the areas in which we can make a real difference, we can actually reach this empowerment. And with empowerment comes responsibility. It's something that already joins with the philosophy of Pharmaceutical Care. So we have to work a lot this question of responsibility. Because if I can, if I am, I also have to take responsibility." 


\section{Pharmacist 2}

The theoretical background of the CMM service points to the importance of to attending a social need [20]. In the context of medication use, it means the need for a professional to hold accountability for the patient's pharmacotherapy [3]. When we started this work, Pharmaceutical Care Practice was utilized as the philosophical framework for the Department of Pharmacy Services. The adoption of this philosophy points to the need for this professional to take on new responsibilities and contributes to the definition of the pharmacist as a health care professional.

As pointed out in the literature about the role of the pharmacist, the priority of his performance was discussed within the team [21]. The team realized that the management of drug supply, logistics and administrative activities are vital because the drug is the technology we manage in practice. However, it is not enough to have the drug if it is not well used by the patient. This discussion highlighted the need for an organisational model for the department including both, inventory management and pharmacy clinical service.

"We need to work as a group because it is not enough to deliver CMM in the clinic if the drug is not available to the patient. So it is extremely necessary to work this as a team, with pharmacists in every corner. Be able to reach as much of the population as possible, because unfortunately, we are not enough pharmacists to be in all clinics. And if you don't have it [the drug] it doesn't help, because the majority of people cannot purchase it."

\section{Pharmacist 3}

\section{Learning to delegate tasks}

The reorganisation of pharmacists' activities to guarantee the implementation of CMM services, as well drug supply logistics, demanded a critical assessment of which activities should be performed exclusively by pharmacists and which should be delegated to others. The team realized that the operationalization of administrative tasks could be delegated to pharmacy attendants. Therefore, they were trained by pharmacists. The team understood it was very important that all personnel incorporated the philosophy of pharmaceutical care as the mission of the department. In the public service context, the preparation of the attendant is a continuous challenge as there is a high turnover of human resources. In addition, many professionals often times do not have the technical training required to deliver pharmacy services. This is highlighted in the following narrative:

"For example, just like this issue of stock that we're trying to minimise errors. If you don't explain to the attendant, to tell him that [drug delivery] is important. because it's so automatic, it is to provide drugs, provide drugs, but until you create an entire situation in which he or she is able to understand what is important, that it is not just delivering the drug. Having an organised stock and a pharmacy attendant that can check if the drug is the right one for that patient and the patient has the basic information to make the right use of it. This will reflect on many other actions. So, the pharmacist has to be there at the pharmacy to oversee them."

\section{Pharmacist 2}

Finding a path contemplating drug supply management and clinical service

We seek to organize the department in such a manner that direct patient care was incorporated into the team's activities, without neglecting the drug supply management. As previously mentioned, there was not any standardization of procedures and functions when we first started this project. Thus, we opted for an organization in which pharmacists' tasks were clearly defined. Initially, clinical and administrative functions were divided into two different areas. While the first one dealt with the responsibility associated with taking direct care of patients (through the provision of CMM services, working close to the health care team, as delivering as conducting operative groups), the second one was associated with management functions (personnel management, drug supply, and other administrative functions). Nevertheless, results were different from expected.
The separation between clinical and administrative pharmacists caused disputes among professionals. The main reason was that limits of responsibilities were unclear. The same health care team receives intervention from both, clinical and administrative pharmacists. The latter group was uncomfortable with that, feeling devalued when compared to the clinical staff. In other words, clinical pharmacists were perceived as more important, as well as more skilled, than their administrative counterparts.

"No, my practice was not very consolidated and the girls (health care team) also questioned a lot. But why you (administrative pharmacist) and she (clinical pharmacist) are here? And I really did not have many arguments. Her work is different from mine; she will be following up with patients. But why you can't do it? Initially, I feel devalued by the team questioning it."

\section{Pharmacist 1 acting as administrative pharmacist}

The way pharmacy services were initially organized, clinical pharmacists were able to act within the primary care units, keeping a closer relationship with other healthcare professionals and building a stronger identity as a provider. Conversely, administrative pharmacists kept superficial relationships with health care teams, focusing their actions mostly in inventory management, remaining isolated in the pharmacy. Such organization has reduced their empowerment and motivation.

"I think so, an important point to empower a person, you need to have contact. Now, in the new unit, I'm having this opportunity. This is really useful! It is crucial! Someone [healthcare team member] sees you, and knows he can count on you when he needs."

\section{Pharmacist 4 acting as administrative pharmacist}

Despite difficulties in approaching the team, in places managed by an administrative pharmacist, the organization of drug supply has been improved and the distance between the pharmacist and the patient has been decreased. Also despite having predominantly administrative tasks, these professionals have demonstrated an interest in offering the CMM service, as illustrated bellow.

"I finished college a while ago, right. And I did not have contact with comprehensive medication management services. It's something that was built after I graduated from pharmacy school. It is something new. This is a difficulty I have. But I want to learn it. I intend to learn it. It is my goal."

\section{Pharmacist 1}

Therefore, reflections and experiences of the team indicated that separation between two types of pharmacists, administrative and clinical, was detrimental to the relationships within the group and to the sense of belonging to the department. However, the attempt to have the same pharmacist to accumulate administrative and clinical functions was difficult as well, since these activities require very different kinds of knowledge, attitudes and behaviours from the professional. The following excerpt presents the experience of a pharmacist acting in both areas:

"It is not enough if I try to do it (administrative service) in the intervals between patient consultations because you're thinking clinically and you have to turn to the administrative and back to the clinical. and it is so complicated!"

\section{Pharmacist 5 acting both in clinical and administrative functions}

\section{A pharmacy service model promoting access and appropriate use of medicines}

In response to the experiences of pharmacists, we created an organisational model for structuring the Central Pharmaceutical Supply (CPS), where one pharmacist was allocated to act at the central level, working as the main supervisor of the inventory management of all pharmacy units. The other pharmacists work mainly as clinicians, with the following responsibilities: (i) training and supervision of pharmacy attendants, (ii) patient counselling, and (iii) provision of CMM services. Thus, currently, medication delivery has been carried out exclusively by attendants, leaving pharmacists free to perform individualised patient care. The structuring of CPS supporting the inventory management of all satellite pharmacies 
enabled pharmacists' engagement with the patient and with the healthcare team, as depicted in the following account:

What disturbed me was that going back and forth between patient consultations and fixing a dispensing error. This is not happening anymore, let me be clear. Dispensing with the system, then back to the patient. then I'm in the middle of patient care; the attendant interrupts me. it was in the beginning. This was very difficult because I was thinking about two things at the same time. (.) Of course [in the new model] we have new procedures, guidelines and it is very calm."

\section{Pharmacist 5}

This model also allowed the standardization of pharmacists' work with the patient (delivering CMM services). There was only one clinical pharmacy service being provided in all pharmacy units of the city, and drug supply was maintained. Also, all department activities were based on the philosophy of Pharmaceutical Care Practice. The collective work enabled the empowerment and commitment of professionals. Creation and consolidation of CPS and delegation of drug delivery functions and stock operations to attendants have freed pharmacists to use their knowledge to benefit patients directly. Thus, these three pillars (practice philosophy, service management and structured CPS) promoted the necessary basis for the pharmacists' work with the patient, as illustrated in fig. 1.

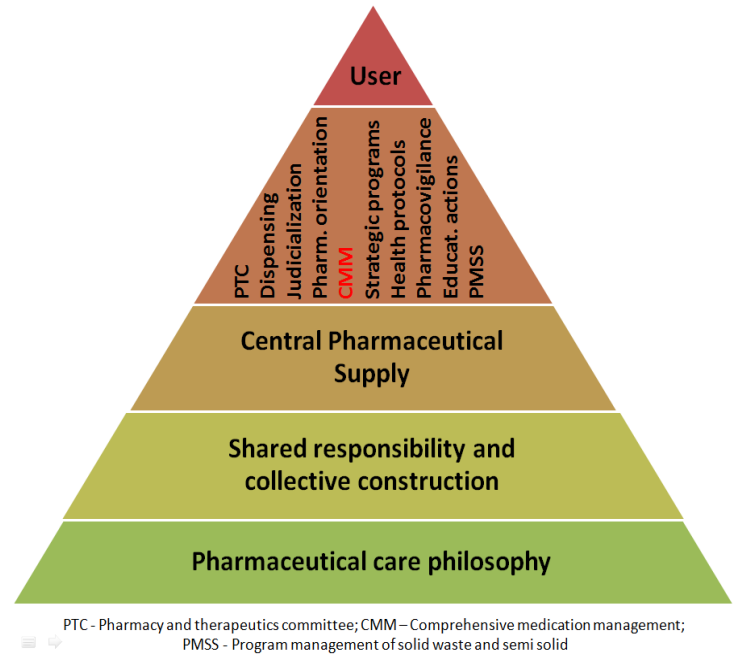

Fig. 1: Department of pharmacy services organisational model

In this new organisational model, all kinds of services delivered by the department have a foundational philosophy, and the patient is the main focus of all activities, whether it is administrative or clinical. A new culture has been gradually built, allowing pharmacists to become active members of healthcare teams, even in clinics without a pharmacy. The team understood that separating the image of the CMM provider from dispensing activities was an important accomplishment of this action research project.

Contributions of action research to the management of pharmacy services and the empowerment of pharmacists

Action research became an instrument for reorganizing pharmacy services in a group, as it promoted constant re-evaluation of its actions to achieve the proposed results. According to Lewin (1945), changes in values, perceptions and behaviours compose an integrated standard for the individual (what he called a "change of culture"). Since action is guided by perception, a change in the behaviour presupposes the perception of new facts and values, not just aspired, but projected (what he called "action-ideology") [22]. The reflective character of action research allowed the group to realize its new role as part of the healthcare team, and recognize the best way to assume direct responsibility for the patient. From the group's perspective, management became an instrument to plan, implement and evaluate the most effective actions. Thus, the cyclical spiral of action research enabled the restructuring of pharmacy services into two cycles, as described in table 1.
The collective construction guided by the reflective character of action research fostered the empowerment of the team of pharmacists, as exemplified bellow:

"This matter of empowerment comes with time, isn't it? The person wins it! It's something that you have to chase, but with time. So, personally speaking, I'm starting to feel it now. After one year, right. One year has passed, and now I'm starting to see the horizons. Before I was trying to imagine. how I could do all this?"

\section{Pharmacist 4}

The active participation of pharmacists in the service building process allowed them to reflect not only about the service itself but also about their own individual performances. Thus, it also became an incentive for the personal development of those involved.

"Why I found interesting to participate? Because by participating actively I was much more involved, and that helps. And participating, I also realize once again my limitations, and thus I have to grow."

\section{Pharmacist 2}

\section{DISCUSSION}

Studies on the routine of pharmacists indicate difficulties regarding the organization of work and the lack of a consistent view of the activities to be developed, lack of human resources, and underutilization of pharmacy services [23, 24]. In our work, we perceived the necessity for innovation in the organization of pharmacists' activities as they assume administrative and clinical responsibilities.

This change of operation has found some challenges: (i) lack of clarity of the pharmacist about his or her responsibilities in Primary Care; (ii) resistance of some pharmacists to explore new working possibilities currently demanded by health care systems, more focused on results and on decreasing health care costs; and (iii) lack of experience of most pharmacists to work as part of a multidisciplinary healthcare team.

By developing our work, it became clear that the clinical work of pharmacists must occur at the same time that administrative work is able to guarantee access of patients to quality medications. However, these are two different types of services demanding diverse competencies from pharmacists. Also, this research pointed out that several activities currently performed by pharmacists can be delegated to either pharmacy attendants or technicians. Pharmacists need to reflect about how they can maximize their impact on the health care system. Throughout this project, we realized the need to ask hard questions about the premises and goals of pharmacy services and how those meet society demands, so that we could redirect the actions of this professional [25]. It was clear from the beginning that pharmacists recognized their responsibility for the results of patients' pharmacotherapy. Nonetheless, there was no clarity regarding the limits of their actions in the context of Primary Care. Action research has become a valuable tool to encourage the team to think about their roles and functions in the Department of Pharmacy Services of Lagoa Santa. Based on group reflections and planning, and taking care of patients on a daily basis at clinics, pharmacists were able to reinvent their identity as healthcare professionals and redefine their responsibilities towards the patient and other team members.

Given the current scenario of the SUS in Brazil, which employs few pharmacists in the context of Primary Care, there is an evident need to identify which functions must be carried out exclusively by the pharmacist and which can be delegated. The pharmacist is usually the last health professional to interact with patients before they make use of their medications, and his performance can significantly influence patients' drug-related decision-making processes [26]. The pharmacist's engagement with the provision of CMM services does not mean this professional shall become unavailable to the patient in the pharmacy. On the contrary, as pharmacists start being recognised as health care providers, they shall be more demanded to perform additional clinical activities, such as counseling, medication 
reconciliation and patient education, among others. Therefore, with time, this professional shall use the best of his abilities and knowledge assisting patients to obtain the best results from their medications.

Table 1: Action research cycles

\begin{tabular}{|c|c|c|c|}
\hline & Evaluation & Action & Emerging facts \\
\hline 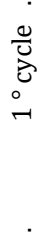 & $\begin{array}{l}\text { - Pharmacist seen as a drug dispenser, } \\
\text { not as a healthcare professional } \\
\text { The role of the pharmacist as a } \\
\text { provider and a member of the team were } \\
\text { unclear to them }\end{array}$ & $\begin{array}{l}\text { - Pharmacist insertion into the healthcare } \\
\text { team } \\
\text { - Separation between administrative and } \\
\text { clinical pharmacists } \\
\text { - Clinical pharmacist working in several } \\
\text { teams to understand where CMM services } \\
\text { should be inserted }\end{array}$ & $\begin{array}{l}\text { - Little improvement in recognition of the } \\
\text { pharmacist as a provider } \\
\text { Pharmacists not considered part of the team } \\
\text { Problems in inventory management } \\
\text { - Few pharmacists delivering CMM services }\end{array}$ \\
\hline 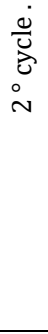 & $\begin{array}{l}\text { Difficulty in defining the identity and } \\
\text { functions of pharmacists by the } \\
\text { pharmacist team and other professionals } \\
\text { Dissatisfaction of administrative } \\
\text { pharmacists for not delivering CMM } \\
\text { Few patients with access to CMM }\end{array}$ & $\begin{array}{l}\text { - Creation of CPS to support drug supply } \\
\text { management } \\
\text { - Technical responsibility and clinical } \\
\text { service assignments for all pharmacists of the } \\
\text { teams } \\
\text { - Pharmacists dedicate more time to work } \\
\text { with health teams } \\
\text { - Drug distribution and delivery performed } \\
\text { exclusively by administrative personnel }\end{array}$ & $\begin{array}{l}\text { Empowerment of administrative pharmacists } \\
\text { who have decided to learn and provide CMM } \\
\text { services } \\
\text { - Expansion of CMM with greater integration of } \\
\text { pharmacists with the teams } \\
\text { Greater team collaboration in the realization } \\
\text { of CMM } \\
\text { - Improvement of drug supply management } \\
\text { team Recognition of the pharmacist as a health care } \\
\text { teamer }\end{array}$ \\
\hline
\end{tabular}

CMM: Comprehensive medication management; CPS: Central pharmaceutical supply

Our study highlighted the need for an organizational model of pharmacy services that contemplates both, drug supply management and pharmacy clinical services. It requires collaborative work by a team of pharmacists that understand the need to move forward towards patient care without compromising access to medicines.

Our study also corroborates the literature on several issues [23, 27]. The education of pharmacists does not prepare them to work in a group. Also, it does not make clear their unique role nor provides the necessary tools for them to work in an interdisciplinary manner. One can see the existence of a dichotomy between theory and practice in the training of pharmacists. While the academic discourse addresses interdisciplinary work, practice is still guided by disciplinarity [28].

Development and implementation of clinical services involve profound changes, which require the will of the pharmacist and the partnership with other professionals. Action research creates a platform that supports awareness and the possible inclusion of these partners [29]. In the studied scenario, our research methodology has become a facilitating agent in the pharmacist's relationship with other pharmacists and with other healthcare professionals.

In developing and learning about its own practice, action research encourages participants to become reflective about what they are able to learn about themselves, personally and professionally speaking, and what they are able to learn about their work, their organization and their target audience [30]. According to Freire, oppression means not allowing someone to critically reflect upon himself, upon his fellows and upon the world around [31]. Reflective practice makes participants more aware and critical about their activities, and more confident on their actions, becoming coresponsible for improving the practice, encouraging a culture of empowerment [32].

It is critical to redefine the pharmacist's role. This professional feels insecure about delegating functions to the attendants and assume new roles that should be accomplished together with the patient. Autonomy is seen as an essential element of liberating praxis, with the capacity to transform reality. However, when desolated by fear of freedom, individuals can simply remain in their own reality [33]. Rosenthal and Tsuyuki (2010) highlighted the pharmacist's culture as a barrier to the change of operation, and cite some "personality traits" that make up this culture and directly influence their behavior [34]. Among them, the authors highlight the lack of trust, fear of new responsibilities, paralysis in the face of ambiguity, need for approval and risk aversion.

This action research allowed researchers and participants to collaborate in a systematic way, through an integration process between research, reflection and action, continuously resumed in the form of cyclic spirals. This process provided the time and space to the cognitive/emotional apprehension of new situations experienced by the whole group (pharmacists and researchers) [10, 35]. Through cyclic spirals, action research became a participatory management tool, since it allowed the group to evaluate the scenario, make the necessary decisions together and evaluate results. These cycles made possible to review the pharmacist's role in Primary Care and enabled the group to find the best organizational model for an efficient inclusion of this new role. This instrument enabled greater awareness of those involved in the project as a whole, and of their performance in the group. As reported by Nørgaardand Sørensen (2016) [36], we realized that action research as a management tool also has negative aspects, such as increasing the time required to conduct the project, considering the need for involvement and participation of all in the collective decision-making process.

According to Woods et al. (2011) [37], to modify competences of a person, it is vital a change in the understanding she possesses about her own work and, therefore, about the meaning of what she intends to do. Thus, action research became a change catalyst of the pharmacist's actions in Primary Care, especially by facilitating their awareness about their activities and goals. The experience of the group and the time we spent to reflect on this experience were important for us to find an operating model for the Department of Pharmacy Services that was feasible in the context of SUS and effective to allow the participation of all pharmacists.

One of the limitations of this study relates to the number of participants involved. As previously mentioned, Lagoa Santa is a small, midsize city, and its population demands less healthcare professionals when compared to large municipalities. A small number of pharmacists in the team facilitated their interaction with the research and management process, contributing to the empowerment of those involved. No doubt, scenarios with a greater number of professionals would demand greater effort to involve everyone in the process, requiring more specific strategies and possibly more time spent in the study.

\section{CONCLUSION}

In our research scenario, we faced many challenges to motivate pharmacists to take direct patient care responsibilities. Some participants were open to the new clinical role, while others were skeptical, fearful or not enthusiastic to work as part of a team. Sometimes, even the patient, the greater beneficiary of a clinical pharmacy service, did not understand the benefits of having a pharmacist to assist him with his pharmacotherapy. In addition, 
pharmacists faced situations they were not prepared for, basically due to lack of appropriate training in pharmacy school. So many challenges required pharmacists to innovate and reinvent their practice on a daily basis.

Such obstacles sometimes caused discouragement and the team lost sight of its objectives and mission. However, meetings and reflections promoted by the action research process were key tools for motivating the team in the face of difficulties and to allow us to recognize our mistakes. Group discussions helped us to understand the strengths and weaknesses in the performance of each one of us and of the department. We also recognized opportunities that helped us to achieve our goals. Certainly, we had disagreements in this trajectory. Not all professionals showed the same empowerment, but teamwork helped alleviate difficulties and motivated the group, despite numerous disruptions.

As future work, we intend to continue using action research as one of the management instruments of the Department of Pharmacy Services in order to establish a process of constant evaluation, standardization and improvement of CMM services in Lagoa Santa/MG, Brazil.

\section{CONFLICTS OF INTERESTS}

All authors have none to declare

\section{REFERENCES}

1. Saturnino LTM, Perini E, Luz ZP, Modena CM. Farmacêutico: um professional em busca de sua identidade. Rev Bras Farm 2012;93:10-6.

2. Marin N, Luzia VL, Osorio-de-Castro CGS, Machado-dos-Santos S. Assistência farmacêutica para gerentes municipais. 20 ed. Rio de Janeiro: OPAS/OMS; 2003.

3. Herpler CD, Strand LM. Opportunities and responsibilities in pharmaceutical care. Am J Hosp Pharm 1990;47:533-43.

4. Ramalho-de-Oliveira D. Atenção farmacêutica: da filosofia ao gerenciamento da terapia medicamentosa. 1 ed. São Paulo: Racine; 2011.

5. Nace Dk, Grundy P, Nielsen M. The Patient-Centered Medical Home: Integrating Comprehensive Medication Management to Optimize Patient Outcomes. 2 Ed. Resource Guide; 2012.

6. Freitas EL, Ramalho-de-Oliveira D, Perini E. Atenção farmacêutica-teoria e prática: um diálogo possível? Acta Farm Bonaerense 2006;25:447-53.

7. Cook T. Reflecting and learning together: action research as a vital element of developing understanding and practice. Education Act Res 2004;12:77-98.

8. Bridges J, Meyer J. Exploring the effectiveness of action research as a tool for organizational change in health care. J Res Nurs 2005;12:389-99.

9. Roberts AS, Benrimoj C, Chen TF, Williams KA, Hopp TR, Aslani P. Understanding practice change in community pharmacy: a qualitative study in Australia. Res Soc Adm Pharm 2005;1:546-64.

10. Koch T, Kralik D. Participatory action research in health care. Australia: Blackwell Publishing Ltd; 2006.

11. Adler N, Shani AB, Styhre A. Collaborative research in organisations: Foundations for learning, change, and theoretical development. Estados Unidos da América: Sage Publications; 2004.

12. Vallenga D, Grypdonck MHF, Hoogwerf LJR, Tan FIY. Action research: what, why and how? Actaneurol Belg; 2009. p. 81-90.

13. Dustman EL, Kohan MB, Stringer ET. Starting small and building out with ernie stringer: personal insights into action research and educational change. Action Res 2014;12:426-3.

14. Reason P, Bradbury H. The SAGE handbook of action researchparticipative inquiry and practice. 2 ed. Londres: SagePublications; 2008.

15. Zaheer-Ud-Din B. Pharmacy Practice Research Methods, Auckland: Adis; 2015.

16. Waterman H, Marshall M, Noble J, Davies H, Walshe K, Sheaff R, et al. The role of action research in the investigation and diffusion of innovations in health care: The PRIDE Project. Quality Health Res 2015;17:373-81.
17. Ryan F, Coughlan M, Cronin P. Step-by-step guide to critiquing research. Part 2: Qualitative research. Br J Nurs 2007;16:738-44.

18. Bazeley P. Analysing qualitative data: more than 'Identifying Themes'. J Qualitative Res 2009;2:6-22.

19. IBGE: Instituto Brasileiro de Geografia e Estatística [internet]. Cidades. Available from: http://cidades.ibge.gov.br/xtras/ perfil.php?lang=andcodmun=313760andsearch=minasgerais|lagoa-santa. [Last accessed on 10 Mar 2016]

20. Cipolle RJ, Strand LM, Morley P. Pharmaceutical care practice: the patient-centered approach to medication management. New York: McGraw-Hill; 2012.

21. Srikanth MS, Ramesh Adepu, Nagaraj S. Impact of an educational intervention on knowledge, attitude, and practices of urban community pharmacists toward adverse drug reaction reporting in a South Indian city. Asian J Pharm Clin Res 2016;9:140-4.

22. Lewin K, Grabbe P. Conduct, knowledge and the acceptance of new values. J Soc Issues 1945;1:53-64.

23. Oliveira AF. A percepção dos farmacêuticos como profissionais da atenção primária de saúde no SUS de fortaleza-CE [dissertação]. [Ceará]: Universidade Federal do Ceará; 2008. p. 123.

24. Furtado BT. O farmacêutico na atenção básica: a experiência da equipe de programa saúde da família frente à atenção farmacêutica [dissertação]. [Belo Horizonte]: Universidade Federal de Minas Gerais; 2008. p. 99.

25. Gomes CAP, Fonseca AL, Machado MC, Rosa MB, Fassy MF, Silva RMC, et al. A Assistência Farmacêutica na Atenção à Saúde. Belo Horizonte: Funed; 2010.

26. Karthikeyan G, Ranganayakulu D. Benefits of clinical pharmacists pharmaceutical care intervention to the quality of patient's life and control hypertension. Asian J Pharm Clin Res 2014;7:223-6.

27. Alano GM. Reflexão e contribuição para uma nova prática-os serviços farmacêuticos voltados ao paciente sob a perspectiva de farmacêuticos do Estado de Santa Catarina [dissertação]. Universidade Federal de Santa Catarina; 2005.

28. Ramalho-de Oliveira D. Por uma formação crítico-humanista do profissional da atenção farmacêutica: Um ensaio reflexivo. Red Sudam Atención Farm 2011;5:1-10.

29. Sørensen EW, Haugbølle LS. Using an action research process in pharmacy practice research-a cooperative project between university and internship pharmacies. Res Soc Adm Pharm 2008;4:384-401.

30. Ngwerume KT, Themessl-Huber M. Using action research to develop a research aware community pharmacy team. Action Res 2010;8:387-406.

31. Coscrato G, Bueno SMV. Pesquisa qualitativa sobre humanização em saúde mediatizada por pesquisa-ação. Saúde e Transformação Social 2010;1:120-8.

32. Nichols R. Action research in healthcare: the collaborative action research network health care group. Edu Action Res 1997; 5:185-92.

33. Barreto RO, Paula APP. "Rio da Vida Coletivo: empoderamento, emancipação e práxis. Rev Adm Pública 2014;48:111-30.

34. Rosenthal M, Austin Z, Tsuyuki RT. Are pharmacists the ultimate barrier to pharmacy practice change? Can Pharm J 2010;143:37-42.

35. Franco MAS. Pedagogia da pesquisa-ação. Educ e Pesqui 2005;31:483-502.

36. Nørgaard LS, Sørensen EW. Action research methodology in clinical pharmacy: how to involve and change. Int J Clin Pharm 2016;38:739-45.

37. Woods P, Gapp R, King MA. Researching pharmacist managerial capability: Philosophical perspectives and paradigms of inquiry. Res Soc Adm Pharm 2011;11:265-79.

\section{How to cite this article}

- Grazielli CB De Oliveira, Mateus R Alves, Djenane Ramalho-DeOliveira. Action research as a tool for transformation of the pharmacist's praxis in primary care. Int J Pharm Pharm Sci 2017;9(3):180-185. 